ether, the following data were elicited: promontory not reached, the hoad pushed to the level of the ischiatic spines. Three hougies were inscrted. On June 7th, as labour had not started, the bougies were removed and four fresh ones inserted, but in spite of this, as well as oil and quinine, there was no labour. On June 10th she left the hospital against our wishes. She was normal in every way.

On June 21st she was readmitted, and said she had felt quite well until 9 p.m. on June 20th, when she had a rigor. She had another at 9 a.m. on June 21st, when the temperature was $102^{\circ} \mathrm{F}$. On her readmission she appeared ill, and as it was thought possible she had influenza, aspirin was administered every four hours.

On June 22nd, soon after midnight, she had a very severe rigor, which lasted five minutes. Temperature $101.2^{\circ}$, pulse 110 respiration 24; profuse sweating, no oedema. The tongue was clean and there were no chest or abdominal symptoms. Blood was taken for culture, and $20 \mathrm{c.cm}$. of antistreptococcus serum and 7.5 grains of quinine were administered intramuscularly. No history of vaginal discharge could be elicited. The foetal heart was 165 to 170 , but there were no pains or history of labour. About an hour later the membranes ruptured, solid meconium came a.way, and she complained of sudden abdominal pain. On examination the uterus was tender. Careful interrogation elicited the fact that coitus had taken place on June 12th-that is, five days after the second insertion of bougies. A diagnosis of coitional sr psis along the track of the bougies was made, and in order to save her life and that of the child, who showed danger signs (meconium, quick foetal heart), Caesarean hysterectomy was decided on. At 2.35 a.m. on June $22 n d$ an abdominal incision long enough to allow extcriorization of the uterus from the symphysis upwards was made. The abdominal wall was protected by coverings, and the intestines by large wipes. After the uterus had been delivered outside the abdomen, the infant was delivered alive; the placenta was left in situ, the uterus stitched, and a speedy total hysterectomy done. The parametria were drained by the vagina, and a tube was placed in the cul-de-sac and brought out through the lower abdominal incision.

The temperature and pulse were normal from the time of the operation, but the baby developed a streptococcal rash and died on the twenty-fourth day.

Sections from the placental site, which was rather low, showed tense infiltration with inflammatory cells. Here and there ocdematous areas and old interstitial haemorrhages were found; cspecially near the cervix. There were enormous numbers of plasma cells in all the sections. No organisms were found, but there was. marked inflammatory reaction. There were no spirochaetes in the placenta. The blood and uterine cultures were negative.

An examination of the husband revealed pus cells in prostatic sinears,

This was evidently a case of true infection from coitus along the track of the bougies. It must not be regarded as necessitating the abolition of the bougie method of inducing labour; it should be regarded as a warning not to allow hospital patients to be discharged after bougie failure; if the patient persists in leaving, she should be warned that she will not be readmitted.

The treatment carried out was drastic, but it was lifesaving; there was no doubt about the diagnosis, and if heroic measures had not been taken death of both mother and child seemed to be a certain outcome; in fact, in true pre-labour sepsis, where the upper segment becomes involved, the only treatment is Caesarean hysterectomy with thorough drainage.

A curious coincidence was elicited in this case. The husband of the patient had been married before; his wife had died after Caesarean hysterectomy for accidental haemorrhage at the time when this treatment was the most customary.

The notes of the cases reported were taken by my assistants Drs. Taylor and O'Donel Browne; the pathological data were recorded by the pathologist to the hospital, Dr. F. S. Borrke.

It is sometimes customary to give statistics at the conclusion of a paper such as this. As the number in the Rotunda reports is so small we do not projose to enter into this phase of the subject.

\section{Summary and Conclusions.}

1. The indications for the performance of Caesarean hystercetomy aje given.

2. The place of the operation for fibroids is small, but for carcinema is very definite. A case of the latter is reported.

3. Sterilization. by hysterectomy is seldom indieated, for other simpler methods are preferable.
4. Ante-partum haemorrhage and the toxaemias do not rank as indications at the Rotunda.

5. Rupture of the uterus sometimes demands its performance, but contraction ring dystocia and neglected shoulder presentation are not indications.

6. Sepsis pre-partum sometimes demands this radical procedure. An interesting case of coitional sepsis is described in detail.

1 Nyhoff : Vedlerl. Tijlechl REFERENCES.

Anderodias and Loubat: Bull. Seesk., 1925, lxx, 502

3 Goldstein and Murphy : Amer. Journ. Obstet., xviii, 2, 189.

4 Murphy : Ibid., xriii, 2, 178.

Muret: Gynécul. et Obstít., xx, 3,277.

Andebert, and Fournier: Buli. Soc. d'Obstét. et de Gynécol., Tr. 8 1921,796

S Solomons and Taylor: Jomm. of Obstet. and Gynaecol. British Empire.

9 Falkiner Trans. Roy. Acal. of Med. in Ireland, February 14th, 1930.

In addition, among others, the following important papers have appeared during the past ten years.

Cacsarran Hystcrectomy for Fibroids.

Ernst: Bruxelles-1éd 1928 rii. 1458 Paquet and Béghin : Bulll. Soc. ilobstét. et de Gynécol., 1927, xvi, 146.
Gross: Ibid., 1925, xiv, 521.

Spencer: British Medical Journal, 1925, ii, 647.

Anderndias, Laconture, and B'Jursier : Bulli. Soc. d'Obstét. et de Giynécol.,

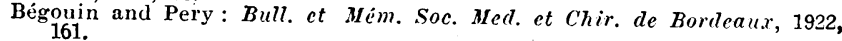

Schockarsb: Gymécol. et Ohstét.. 1922, vi, 346.

Autefage: Bulli. Soc. llobstét. et de Gyncecol., 1921, x, 628

Duvergey: ('az. Hebd. de Sci. Médl. de Bordeaux, 1920, xli, 57.

Voron and Vergnory : Bull. Soc. d'Obstét, et de Gynécol., 1920, ix, 371.

For Cancer of the Utcrus and of the Orary.

Commandeur, Eparvier, and Michon: Bull. Soc. d'Olstét. et de Gynécol. de Paris, 1926, $\mathrm{xv}, 59-62$

Luker : Proc. Roy. Soc. Mled., 1921, 22, xv.

For placcnta Pracia.

Solaroli : Clin. Obstet., 1928, $\mathrm{xxx}, 242$

Rivière and Laconturé: Bull. Soc. d'obstét. et de Gynécol., 1923, xi, 427.

\section{MEASLES IN A MAN OF FIFTY-SEVEN.}

BY

ARTHUR J. HALL, M.D., F.R.C.P., PROFESSOR OF MEDICINE, SHEFFIELD UNIVERSITY.

Is any country in which measles is more or less constantly prevalent its occurrence in an adult is as rare as its occurrence in childhood is common." The outbreak of measles in the Faroe Islands, recorded by Panum of Copenhagen, showed that adults are as susceptible as children. It was conveyed there in 1846, after an interval of sixty-five years, and 6,000 out of the 7,782 inhabitants were infected. Age was no bar; practically no one escaped who was exposed to it. In this country it occasionally affects young adults, but such cases are not common. The case here briefly narrated of a first attack of measles in a man in his sixth decade is so unusual that it seems worth recording.

On: December 24lin Mr. X, a married man aged 57 , began to be feverish and out of sorts. Catarrhal symptoms, though not particularly noticeable at first, were present. The case was thought to be one of influenzal type. The temperature was slightly raised. On December 27th it fell somewhat, and he seemred rather better; also on the morning of the following day. The attack was thought to be passing off. In the evening of the 28th, however, the temperature rose to $103^{\circ}$, and a rash was noticed. On December 29th thie rash was much more extensive, and the temperature $104^{\circ}$. There was also considerable bronchial catarrh. His medical attendant, Dr. Parrett of Thorne, recognized the nature of the disease as soon as he saw the rash. $\mathrm{He}$ was naturally surprised and a little anxious, because tire patient had for some years been subject to bronchitis in the winter months.

On December 31st, as the temperature was still high, the pulmonary symptoms increasing, the pulse rate going up a little, and as there was also some cyanosis, Dr. Parrett asked me to meet him in consultation. The patient was mentally quite clear and alert. There had been no delirium at any time. The cough was very troublesome, and rhonchi were audible over the lungs, but there was no real dyspioea. The pulse was 88 and regular. The face was dusky red; slightly cyanosed. The conjunctivä were injected, the tongue was an intense fiery red with whitish patches here and there. The rash was more marked on the face, 
neck, and trunk than on the limbs, and consisted of closely packed but discrete crescentic and irregular macules, showing innumerable typical bright red papules, many of which were distinctly petechial. This necessarily produced a considerable variety of colours, and as he was a big man, with a very long and broad back, the total effect of this large mass of brilliant colouring was unusually striking.

Prognosis was difficult. Measles at 57 years of age is quite outside one's experience. It seemed just possible that as this disease gives rise to the more severe bronchial complications in infancy it might also be more serious in this respect in the later years of life, especially in a person already subject to bronchitis. $\Lambda s$, however, the pulse was only 88 , and there wore no signs of serious toxaemia, and as by this, the eighth day, the fever had probably reached its height, it seemed likely that the next few hours would bring a general improvement. The only point of doubt was as to the possible extension of bronchial trouble. Our anxiety about this, however, was unnecessary, for in a few hours he began to improve, and after that continued to make an uninterrupted recovery.

It is interesting to surmise how and where he became infected, and still more how it was he had escaped infection earlier in life. As regards the former point, there was an outbreak of measles in the neighbourhood at the time, and an opportunity of infection seems to have been a journey in a public motor bus, just a fortnight before, to and from a neighbouring town some miles away. There were some children in the bus, but nothing is known as to who they were, or if any of them had the disease. Otherwise he led an unusually secluded life. Although married he had had no children. He lived in a large, rather isolated house, and had very few visitors. Curiously enough, his wife is said to have had measles twice, though whether either of the attacks occurred since marriage was not stated.

Students in taking clinical histories often forget to put down the patient's age, and when told to do so are apt to look upon their teachers as rather umnecessarily meticulous. As a matter of fact, in hearing the history of a rase the experienced clinician unconsciously adjusts his thoughts to a certain group of cases directly he hears the patient's age; at any rate, he unconsciously eliminates a considerable number of conditions which he knows are not likely to occur at that particular period of life. Now and again, as in this case, it is the unexpected that happens. When it does, the ordinary clinical values become changed and require rather careful adjustment.

\section{IIIGH BLOOD PRESSURE AND C'HOLLESTERIN.} BY

I. HARRIS, M.D.Königsberg, L.R.C.P.ED., PHYSICIAN TO THE LIVERPOOL HEART HOSPITAL,

AND

I. J. LIPKIN, M.D., Ch.B.LiverP., D.P.H., D.T.M., BIOCHEMIST TO THE LIVERPOOL HEART HOSPITAL.

Nithix recent years various attempts have been made to seek in blood chemistry the causal factor for hypertension. Guanidine and its derivatives, sugar, uric acid, potassium and calcium salts, in abnormal quantities in the bloodeach of these substances in turn has been held responsible for the hypertonic contractions of the vessels in cases of high blood pressure. The latest suggestion is that hypercholesterinaemia is responsible for the production of high

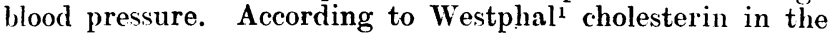
blood circulation affects the ressels in such $\mathbf{a}$ way as to increase their susceptibility to adrenaline. The latter, of course, gives rise to hypertension. This author found in 71 per cent. of his high blood pressure cases an increase in cholesterin content of the whole blood.

Thomas ${ }^{2}$ injected rabbits with cholesterin and observed an increase in blood pressure. Thölldte, ${ }^{3}$ who repeated the experiment, was not able to confirm the findings. While the authorities thus differ as to whether cholesterin directly raises the pressure, greater unanimity exists in regard to cholesterin as a factor in the production of arterio-sclerosis. Tregnbow fed rabbits with cholesterin, and he found, as many others have discorered before him, that arterio-sclerosis develops as a result of this feeding. The arterial pressure, however, did not rise in these cases.
Shapiro $^{5}$ also looks upon cholesterin as the chief factor in the production of arterio-sclerosis. He believes the increase of cholesterin in the blood is due to the activity of certain glands of internal secretion. Zachariae ${ }^{6}$ prepared a kind of vaccine, the purpose of which is to dissolve cholesterin in the blood, and he claims a marked improvement in the condition of his patients as a result of this treatment, the blood pressure becoming low. Askenazy ${ }^{7}$ found an increased cholesterin content in the blood in the great majority of his high blood pressure cases, and he highly recommended rhodan as a solvent of cholesterin in the circulation.

Amidst all the turmoil of conflicting opinion one simple fact stands out: arterio-sclerotic vessels invariably contain deposits of cholesterin and calcium. Our observation is based on actual blood cholesterin content found in hypertonic cases. In our investigation we administered cholesterin to patients, first in the form of food rich in cholesterin content, and subsequently by intramuscular injections, taking the blood pressure reading and determining the cholesterin content of the blood both before and after administration of the substance.

\section{Method of Cholesterin Determination.}

On to a fat-free filter-paper disc, pierced in the centre, and made to fit a specially constricted test tube containing $5 \mathrm{c.cm}$. of chloroform, is pipetted $0.25 \mathrm{c.cm}$. of oxalated blood. The tube is attached to a reflux condenser, and is immersed in a boiling-water bath. After thirty minutes the tube is detached from the condenser and cooled by putting under cold water; chloroform is added to the 5 c.cm. mark. To a similar tube $5 \mathrm{c.cm}$. of a standard cholesterin solution (8 mg. per $100 \mathrm{c.cm}$.) is added. To each tube is added $2 \mathrm{c.cm}$. of acetic anhydride and $1 \mathrm{c.cm}$. of strong sulphuric acid. The tubes are inverted twice to mix well and allowed to stand in cold water for ten minutes and compared in a Klett colorimeter.

The list of cases printed below gives the blood cholesterin of 11 hypertonic patients under observation at the Liverpool Heart Hospital. Cases with pronounced lesion of the kidneys were excluded, as it is known that these give a hypercholestcrinaemia. We do not, however, for a moment suggest that all our cases are of the type of "essential" hypertony. We are definitely of opinion that it is quite impossible to differentiate clinically between "essential" hypertony and hypertony due secondarily to kidney disease; for the kidney efficiency tests give only information in regard to failure of the kidney function, and not in regard to the existence or otherwise of disease of the kidner, and the presence or absence of a trace of albumin and occasional casts does not mean much either way. The variation of blood cholesterin within normal limits is between 160 and 200 . It will be seen that only in one case did the cholesterin blood content exceed 200. At any rate, even if the blood cholesterin were found to be increased, it by no means follows that it is the cause of high blood pressure. It is quite possible that a high blood pressure acting on the liver might produce hypercholesterinaemia.

\section{Blood Cholesterin of 11 Hypertonic Cases under Obscrvation at the Liverpool Heart Hospital.}

CASE 1.-C. M., aged 53. Blood pressure. 225/110; cholesterin blood content, $172 \mathrm{mg}$. per $100 \mathrm{c.cm}$. of blood.

Clinical Signis.-Evidence of gross damage to the heart muscle; the QRS complex pronouncedly abnormal; left ventricle enlarged. Relative aortic and mitral regurgitation. All evidence pointed to a very old-established case of ligh blood pressure.

CASE 2.-A. H., aged 58. Blood pressure, 290/170; cholesterin blood content, $162 \mathrm{mg}$. per $100 \mathrm{c.cm}$. of blood.

Clinical Signs.-Typical case of high blood pressure. No albumin. left ventricle enlarged. Electro-cardiogram apart from left-sided preponderance normal.

Case 3.-F. P.; aged 40. Blood pressure, 190/80; cholesterin blood content, $204 \mathrm{mg}$. per $100 \mathrm{c.cm}$. of blood.

C'linical Signs.-Wassermann test negative. Moderate enlargement of left ventricle; double murmurs at the aortic area. Electrocardiogram normal.

CASE 4.-R. B., aged 45. Blood pressure, 165/95; cholesterin blood content, $196 \mathrm{mg}$. per $100 \mathrm{c.cm}$. of blood.

Clinical Sigms.-Combined valvular lesion, the predominant of which is aortic.

CASE 5.-C. McC., aged 64. Blood pressure, 230/115; cholesterin blood content, $160 \mathrm{mg}$. per $100 \mathrm{c.cm}$. of blood.

C'linical Signs.-Trace of albomin. Enlarged left ventricle; accentuation of second aortic.sound, -Electro-cardiogram normalo 